\section{Sources of Resistance to Phytophthora cinnamomi in Juglans spp. for Potential Rootstocks}

Salvatore Vitale, Laura Luongo, Marzia Scarpari, Lorenza Tizzani, Ivana Garaguso, Massimo Galli, and Alessandra Belisario

Consiglio per la Ricerca in Agricoltura e l'analisi dell'economia agraria (CREA - Council for Agricultural Research and Economics) - Centro di Ricerca Difesa e Certificazione (DC), 00156 Roma, Italy

\author{
Michele Scotton \\ Department of Agronomy Foods Natural Resources Animals and \\ Environment, University of Padova, Legnaro, 35020 Padova, Italy
}

Giovanni Mughini and Maria Gras

Consiglio per la Ricerca in Agricoltura e l'analisi dell'economia agraria (CREA) - Centro di Ricerca Foreste e Legno (FL), 00166 Roma, Italy

\section{Anita Haegi \\ Consiglio per la Ricerca in Agricoltura e l'analisi dell'economia agraria (CREA) - Centro di Ricerca Difesa e Certificazione (DC), 00156 Roma, Italy}

Additional index words. common walnut, English walnut, Juglans major, Juglans microcarpa, Juglans nigra, Juglans regia, Persian walnut

\begin{abstract}
A diverse collection of Juglans species and hybrids with potential to serve as walnut rootstocks was evaluated to identify resistance to Phytophthora cinnamomi, a destructive pathogen affecting commercial production of Persian walnuts worldwide. A total of 35 Juglans genotypes, comprising hybrids and Juglans microcarpa, plus three Juglans regia genotypes as comparison, were inoculated during two seasons (spring and autumn) for 3 years, with two isolates of $P$. cinnamomi. Inoculations were carried out on excised shoots of the different genotypes by replacing a bark disk with a $P$. cinnamomi culture plug. After incubation, necrosis length caused by the pathogen was measured. Data were collected and statistically analyzed with generalized linear mixed models. This work pointed out a seasonal influence on some Juglans genotype response to $P$. cinnamomi: both hybrids and $J$. microcarpa groups were significantly less sensitive in autumn compared with spring $(P=\mathbf{0 . 0 0 0 6})$, thus this condition must be considered when selecting Juglans for resistance to this pathogen. Three genotypes of $J$. regia, known for its susceptibility to $P$. cinnamomi, were used as comparison. Results show good levels of resistance to $P$. cinnamomi in $J$. microcarpa genotypes, confirming literature results. Among $J$. microcarpa genotypes, the $\mathbf{J m i 0 3}$ is quite promising for its in vitro propagation. A number of Juglans hybrids, $\mathrm{H5} / 18,7 / 28,8 / 29,10 / 43$, and $6 / 22$, showed significantly higher levels of resistance to $P$. cinnamomi, compared with susceptible $J$. regia genotypes. Evaluation, in naturally infected fields, of clonal genotypes and seedlingprogenies of resistant genotypes, grafted with commercial walnut varieties, is currently under way and will provide additional information for successful usage.
\end{abstract}

Oomycetes, also known as "water molds," are a group of several hundred organisms including devastating plant pathogens. Among these, Phytophthora spp. are a worldwide threat. Within that genus, $P$. cinnamomi is considered one of the most destructive and invasive species with an extremely wide host range including almost 5000 woody plant species occurring in more than 70 countries (Hardham and Blackman, 2018). P. cinnamo$m i$ economically impacts forestry, agriculture, horticulture, and nursery industries (Belisario et al., 2006; Burgess et al., 2017; Jung et al., 2016; Kamoun et al., 2015; Scanu et al., 2013). This pathogen survives harsh conditions and such capability, could be associated with the production of chlamydospores, plant death, following slow or sudden decline. Severe outbreaks commonly occur when prolonged and repeated flooding take place.

Incidence and severity of walnut decline due to $P$. cinnamomi can be minimized with careful water management and foliar treatments of phosphorous acid (phosphonate commonly referred as Phosphite) (Belisario et al., 2009; Browne et al., 2011). Rootstocks with resistance to this pathogen are needed. Paradox hybrid rootstocks (Juglans hindsii $\times$ $J$. regia) have been reported as tolerant/resistant to several species of Phytophthora (Browne et al., 2011; Matheron and Mircetich, 1985a; Mircetich and Matheron, 1983; Mircetich et al., 1998), but not to P. cinnamo$m i$. A range of walnut rootstocks, suitable to various walnut management conditions and resistant to $P$. cinnamomi, is a priority worldwide. Browne et al. (2015) indicate that genotypes of J. microcarpa, and hybrids: (Juglans californica $\times$ Juglans nigra $) \times J$. regia), (Juglans major $\times J$. hindsii $) \times J$. nigra $) \times J$. regia, and $(J$. nigra $\times J$. regia), were promising for resistance to $P$. cinnamomi. In particular, J. microcarpa $\times$ $J$. regia clone $\mathrm{RX1}$ may represent a resistant rootstock against $P$. cinnamomi attacks.

The aim of our work was to select single genotypes, within Juglans sources available in Consiglio per la Ricerca in Agricoltura e l'analisi dell'economia agraria (CREA) Centro di ricerca Foreste e Legno (FL) of Rome, for resistance to P. cinnamomi. At the same time, progenies from those selected genotypes were tested as rootstock graft compatible with commercial walnut cultivars.

\section{Materials and Methods}

Based on results reported by Browne et al. (2015) and urgency to contain P. cinnamomi damage to walnut cultivation, a selection program was set up to screen a collection of hybrids of $J$. regia, open pollinated with $J$. nigra and/or with $J$. major, as well as a population of $J$. microcarpa for resistance to P. cinnamomi.

Plant materials. A walnut germplasm collection obtained with seeds coming from Asia, North America, and Europe was established (from 1989 to 1992) at the experimental farm of CREA-FL. Of $\approx 100$ single Juglans genotypes present in this collection, a total of 35 genotypes, that in the field showed higher vigor and compatibility of phenological phases, was selected as putative sources of resistance to $P$. cinnamomi. Among those, 23 were interspecific, highly heterogenic hybrid genotype group obtained by open pollination between $J$. regia with $J$. nigra and/or $J$. major (H1/1, 1/4, 2/5, 2/7, 4/ $15,5 / 17,5 / 18,5 / 19,5 / 20,6 / 22,7 / 28,8 / 29,8 /$ $32,9 / 34,9 / 36,9 / 38,9 / 40,10 / 43,10 / 44,12 /$ $52,14 / 60,15 / 63$, and 16/68) (Gaudet et al., 2018) and 12 were single-genotype trees (Jmil, 2, 3, 4, 5, 6, 7, 8, 9, 10, 11, and 12) belonging to $J$. microcarpa var. microcarpa (obtained from Chihuahua, Mexico). Species identification by neutral microsatellite (SSR) (Ebrahimi et al., 2019) is currently examined in more depth by CNR-IRET (Istituto di 
Ricerca sugli Ecosistemi Terrestri, Porano, TR). In addition, three genotypes of $J$. regia (Jr74, 75, and 76) susceptible to P. cinnamo$m i$, were used as comparison and subjected to the same inoculation procedure as genotypes under selection.

For each genotype/tree, 1-year-old shoots, $2-\mathrm{cm}$ in diameter and $1-\mathrm{m}$ in length, excised from the 38 walnut germplasm collection trees, were taken in spring and autumn. They were kept at room temperature in the dark in water buckets until inoculation was performed, within $24 \mathrm{~h}$ (Belisario et al., 2009).

Pathogen culture and pathogenicity tests. From a collection of more than 50 isolates of $P$. cinnamomi from different sources [conserved in "Consiglio per la Ricerca in agricoltura e l'analisi dell'Economia Agraria (CREA) Centro di Ricerca Difesa e Certificazione (DC)"], two highly virulent isolates originating from walnut were selected for pathogenicity tests (Vitale et al., 2018). Isolates CREADCOm202 and CREADC-Om274, obtained from rotted collars of declining English walnut trees located in Venezia province, were used. Each isolate was identified as $P$. cinnamomi by specific amplification of Ypt1 gene sequences as described by Schena et al. (2008).

Tests were conducted by directly inoculating excised shoots using the method described by Vettraino et al. (2001) and Belisario et al. (2009) with some modifications. Inoculations were carried out using a cork borer to remove a 5-mm bark disk from the excised shoot. The bark disk was replaced by a 5 -mm plug of 6day-old $P$. cinnamomi cultures grown on potato dextrose agar (PDA) media. Each inoculation point was then wrapped with 2-parafilm ${ }^{B}$ (Bemis Company, Inc. Neenah, WI) to prevent dehydration and contamination. Each shoot was inoculated in three points (apical, central, and lower). Two points were inoculated with $P$. cinnamomi isolate CREADC-Om202 and CREADC-Om274 each and one point was inoculated with sterile PDA plugs used as control. Three shoots per genotype (replicates) were used. After inoculation, shoots, proximal

Received for publication 28 Dec. 2020. Accepted for publication 18 Mar. 2021.

Published online 14 May 2021.

We greatly thank Steve Sibbett and Alessandro Infantino for their thorough revision of the manuscript and their precious suggestions. We also want to thank the walnut growers ("Nogalba" and "Noceto" Companies) for the technical support to the research and execution of experimental trials for progenies tested for resistance to Phytophthora cinnamomi in naturally infested fields. This work was founded by the Italian Ministry of Agriculture (MiPAAF) within the research project PORT.NOC "Valutazione di portinnesti per la tolleranza/resistenza a Phytophthora e blackline e valorizzazione di varietà di $J u$ glans regia compatibili." Moreover, we thank Luca Ferretti, Emilia Caboni, Francesco Menta, Alvaro Pedemonti, and Enzo Marinelli for their extremely useful scientific and technical support.

A.H. is the corresponding author. E-mail: anita. haegi@crea.gov.it.

This is an open access article distributed under the CC BY-NC-ND license (https://creativecommons. org/licenses/by-nc-nd/4.0/). end down, were placed in 2-L water containing buckets ( $25 \mathrm{~cm}$ diameter) and incubated for $8 \mathrm{~d}$ in the dark at $25 \pm 2{ }^{\circ} \mathrm{C}$ and high relative humidity. After incubation, shoots were barked with a blade and length $(\mathrm{mm})$ of internal necrosis was measured. A total of six inoculation assays were conducted from 2017 to 2019 in both spring (May) and autumn (October), which are reported to be more conducive to Phytophthora infection (Matheron and Mircetich, 1985b).

Data analysis. In a first analysis, a generalized linear mixed model (GLMM) with three completely randomized replicates was fitted according to a full factorial design to test the effect of the following four fixed effects on bark necrosis length: 1) $P$. cinnamomi isolate (three levels: isolate CREADCOm202, isolate CREADC-Om274, and control); 2) group of Juglans genotypes (three levels: J. regia genotypes, J. microcarpa genotypes, and hybrid genotypes between $J$. regia $\times J$. nigra and/or $\times J$ major); 3) Juglans genotype, nested within genotype group; 4) season of inoculation (two levels: spring and autumn). Year was input as random factor. Post hoc multiple comparisons of means for each factor were performed using the TukeyKramer adjustment.

In a first GLMM, all levels were considered for the factor isolate (isolate CREADCOm202, isolate CREADC-Om274, and control) to test effects of the two isolates vs. no inoculation (control). In a second GLMM, only data of two treatments of greatest interest (i.e., inoculation with CREADC-Om202 and CREADCOm274) were considered to eliminate influence of the control on statistical results.

In a second analysis, to identify genotype groups with similar responses to pathogenicity tests, the 38 Juglans genotypes were clustered based on four necrosis lengths calculated as means of each season per each isolate. Euclidean distance, as a similarity function, and the Ward clustering method were used for analysis (Legendre and Legendre, 1998). Genotype clusters significantly different from the others were identified using a permutation procedure called similarity profile routine (SIMPROF; Clarke et al., 2008).

Statistical software used were SAS/STAT version 9 for Windows (SAS Institute Inc, 2002-2012), procedure GLIMMIX to perform GLMM; R 3.0.0 (Core Team R, 2013) with the package CLUSTSIG for cluster analysis and identification of significantly different clusters with procedure SIMPROF.

\section{Results}

A total of 38 Juglans genotypes, divided into three groups (hybrids, J. regia, J. microcar$p a$ ), inoculated during two seasons (spring and autumn) for 3 years, with two isolates of $P$. cinnamomi, showed different responses (Fig. 1).

The difference in necrosis length displayed by inoculated Juglans genotypes during the two seasons analyzed (spring and autumn) is shown in Table 1.

Statistical analyses found no significant difference between the two isolates CREADCOm202 and CREADC-Om274, $P=0.0721$.
No significant interaction between genotype group $\times$ isolate $(P=0.1050)$ and season $\times$ isolate $(P=0.7467)$ was present.

Conversely, significant differences were found between host populations and spring and autumn inoculations (interaction genotype group $\times$ season significant at $P=$ 0.0006: Table 1). Both hybrids and J. microcarpa groups were significantly less sensitive in autumn compared with spring, whereas in the three $J$. regia genotypes, the pathogen sensitivity was high and similar in both seasons. Thus, sensitivity of Persian (English) walnut to $P$. cinnamomi seems indifferent to season. Control inoculations with sterile PDA plugs did not develop infection lesions, except basic necrosis due to wound.

For hybrid walnut genotype group, average spring value lengths were $74.7 \mathrm{~mm}$ [standard error of the mean $(\mathrm{SEM})=5.4 \mathrm{~mm}]$ and 80.4 $\mathrm{mm}(\mathrm{SEM}=5.1 \mathrm{~mm})$ for $P$. cinnamomi CREADC-Om202 and CREADC-Om274 isolates, respectively (Table 1). On the other hand, autumn average values were $41.9 \mathrm{~mm}$ $(\mathrm{SEM}=1.9 \mathrm{~mm})$ and $45.9 \mathrm{~mm}(\mathrm{SEM}=2.3$ $\mathrm{mm})$ for P. cinnamomi CREADC-Om202 and CREADC-Om274 isolates, respectively. This trend was confirmed in J. microcarpa genotype population with spring average values of 59.2 $\mathrm{mm}(\mathrm{SEM}=3.4 \mathrm{~mm})$ and $56.3 \mathrm{~mm}(\mathrm{SEM}=$ 3.5) and autumn average values of $38.1 \mathrm{~mm}$ $(\mathrm{SEM}=2.6 \mathrm{~mm})$ and $37.6 \mathrm{~mm}(\mathrm{SEM}=3.7$ $\mathrm{mm}$ ) for $P$. cinnamomi CREADC-Om202 and CREADC-Om274 isolates, respectively.

Focusing on genotypes (Fig. 1; Table 1), $J$. microcarpa genotypes showed better resistance to $P$. cinnamomi colonization compared with that in the hybrid population, with 48.7 $\mathrm{mm}(\mathrm{SEM}=2.3 \mathrm{~mm})$ and $47 \mathrm{~mm}(\mathrm{SEM}=$ $3.1 \mathrm{~mm})$ against $58.3 \mathrm{~mm}(\mathrm{SEM}=3.4 \mathrm{~mm})$ and $63.1 \mathrm{~mm}(\mathrm{SEM}=3.4 \mathrm{~mm})$, for $P$. cinnamomi CREADC-Om202 and CREADCOm274 isolates, respectively. As expected, highest susceptibility was observed in genotypes of $J$. regia with an average of $91.5 \mathrm{~mm}$ $(\mathrm{SEM}=6.7 \mathrm{~mm})$ and $100.6 \mathrm{~mm}(\mathrm{SEM}=9.1$ $\mathrm{mm}$ ) for $P$. cinnamomi CREADC-Om202 and CREADC-Om274 isolates, respectively (Fig. 1; Table 1). However, the results of the Tukey-Kramer multiple mean comparison obtained from GLMM did not clearly group genotypes by their species membership (Table 2). From all analyses, the hybrid 10/43 followed by Jmi12, 8, 7, and 11, in increasing order of necrosis length (from 29.13 to 39.36 $\mathrm{mm}$ ), were the most resistant (Table 2).

At $P \leq 0.05$ significance level, cluster analysis identified seven genotype groups (Fig. 2). One of them (group 7) included genotypes most resistant to $P$. cinnamomi colonization, namely: H10/43, Jmi12, H6/22, H5/ 18, Jmi11, Jmi7, Jmi8, H7/28, and H8/29.

\section{Discussion}

Phytophthora cinnamomi is one of the most devastating and widespread oomycete species. It kills Persian walnut trees, which are very sensitive to infection by this pathogen, with economic impacts on profitable walnut farming. Considerable research efforts are 

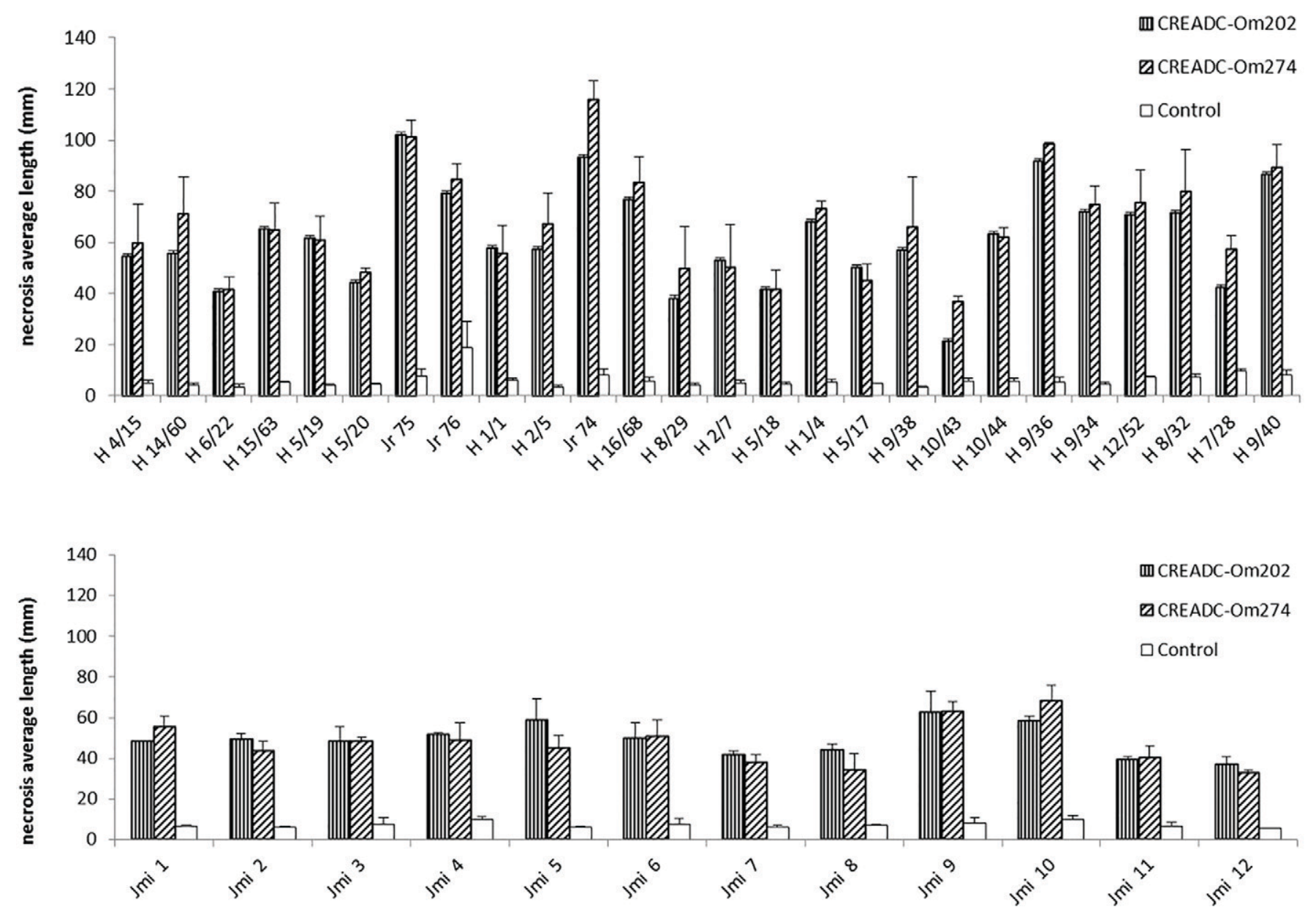

Fig. 1. Susceptibility of excised shoot segments from 38 walnut species and hybrids to Phytophthora cinnamomi. Histograms represent necrosis length extension ( $\mathrm{mm} \pm \mathrm{SEM}$ ) resulting $8 \mathrm{~d}$ after inoculation with the pathogen, averaged on six plug inoculations, with two isolates of $P$. cinnamomi, on 1-year-old excised walnut shoots performed in spring and autumn from 2017 to 2019. Error bars represent the standard deviation. $\mathrm{H}=\mathrm{Hybrid}$ genotypes trees were obtained from open pollination between Juglans regia $\times$ Juglans nigra and/or $\times$ Juglans major; $\mathrm{Jr}=J$. regia; Jmi $=$ Juglans microcarpa var. microcarpa genotypes.

Table 1. Necrosis length ( $\mathrm{mm}$ ) measured on shoots of three Juglans genotype groups inoculated with two Phytophthora cinnamomi isolates in two seasons.

\begin{tabular}{|c|c|c|c|c|}
\hline \multirow{2}{*}{\multicolumn{2}{|c|}{$\begin{array}{l}\text { Inoculation season } \\
\text { P. cinnamomi isolate } 1) \\
\end{array}$}} & \multicolumn{3}{|c|}{ Spring } \\
\hline & & 202 & 274 & Mean \\
\hline $\begin{array}{l}\text { Genotype } \\
\text { group } \\
2 \text { ) }\end{array}$ & $\begin{array}{l}\mathrm{H} \\
\mathrm{Jr} \\
\mathrm{Jmi} \\
\text { Mean }\end{array}$ & $\begin{aligned} 74.7 & \pm 5.4 \\
104.6 & \pm 8.5 \\
59.2 & \pm 3.4 \\
79.5 & \pm 4.0\end{aligned}$ & $\begin{aligned} & 80.4 \pm 5.1 \\
& 118.4 \pm 10.9 \\
& 56.3 \pm 3.5 \\
& 85.1 \pm 4.3 \\
& \text { Autumn }\end{aligned}$ & $\begin{aligned} 77.5 & \pm 5.2 \\
111.5 & \pm 9.1 \\
57.8 & \pm 3.1 \\
82.3 & \pm 4.0 \mathrm{~A}\end{aligned}$ \\
\hline $\begin{array}{l}\text { Genotype } \\
\text { group } \\
2 \text { ) }\end{array}$ & $\begin{array}{l}\mathrm{H} \\
\mathrm{Jr} \\
\mathrm{Jmi} \\
\text { Mean }\end{array}$ & $\begin{array}{l}41.9 \pm 1.9 \\
78.4 \pm 6.9 \\
38.1 \pm 2.6 \\
52.8 \pm 2.2\end{array}$ & $\begin{aligned} & 45.9 \pm 2.3 \\
& 82.7 \pm 8.5 \\
& 37.6 \pm 3.7 \\
& 55.4 \pm 2.6 \\
& \text { Mean }\end{aligned}$ & $\begin{array}{l}43.9 \pm 1.9 \\
80.6 \pm 6.7 \\
37.9 \pm 3.0 \\
54.1 \pm 2.4 \mathrm{~B}\end{array}$ \\
\hline $\begin{array}{l}\text { Genotype } \\
\text { group } \\
2 \text { ) }\end{array}$ & $\begin{array}{l}\mathrm{H} \\
\mathrm{Jr} \\
\mathrm{Jmi} \\
\text { Mean }\end{array}$ & $\begin{array}{l}58.3 \pm 3.4 \\
91.5 \pm 6.7 \\
48.7 \pm 2.3 \\
66.2 \pm 2.8\end{array}$ & $\begin{aligned} 63.1 & \pm 3.4 \\
100.6 & \pm 9.1 \\
47.0 & \pm 3.1 \\
70.2 & \pm 3.2\end{aligned}$ & $\begin{array}{l}60.7 \pm 3.3 \mathrm{~B} \\
96.0 \pm 7.1 \mathrm{~A} \\
47.8 \pm 2.6 \mathrm{C} \\
68.2 \pm 3.0\end{array}$ \\
\hline
\end{tabular}

A generalized linear mixed model found the following significance levels of the tested factors: $P$. cinnamomi isolate (PI), $P=0.0721$; group of Juglans genotypes (GG), $P<0.0001 ;$ Juglans genotype nested within genotype group, $P<0.0001$; Inoculation season (IS), $P<0.0001$; PI $\times$ GG, $P=0.1050$; PI $\times$ IS, $P=0.7467$; GG $\times$ IS, $P=0.0006$. The letters beside the means indicate the result of the mean multiple comparison performed with the Tukey-Kramer adjustment when the model indicated significant among-means differences at $\mathrm{p} \leq .05$. Mean values with the same letter do not differ at $P \leq 0.05$.

1) P. cinnamomi isolate: 202, CREADC-Om202; 274, CREADC-Om274. 2) Genotype group: $\mathrm{H}=$ hybrid genotypes (Juglans regia $\times$ Juglans nigra and/or $\times$ Juglans major); $\mathrm{Jr}=J$. regia $; \mathrm{Jmi}=J u$ glans microcarpa var. microcarpa. being undertaken worldwide to investigate responses of Phytophthora spp. infections to different Juglans species other than J. regia. Resistant rootstocks, graft compatible with the main edible walnut cultivars, have the best potential for the control of this disease. Clonal rootstocks Vlach, VX211, and RX1, were reported in Chile as a solution to adverse $P$. cinnamomi infection (Alvarado et al., 2020), although Vlach and VX211 were not considered resistant to this Phytophthora species in previous literature (Browne et al., 2015).

In the present work, good levels of resistance to $P$. cinnamomi were found in $J$. $m i$ crocarpa genotypes, confirming results described by Browne et al. (2015). Among $J$. microcarpa genotypes, the Jmi3 is quite promising for its in vitro propagation (Gentile et al., 2020). In addition, quite a number of walnut hybrids showed high levels of resistance to $P$. cinnamomi, in particular $\mathrm{H} 5 / 18$, $7 / 28,8 / 29,10 / 43$, and $6 / 22$. Preliminary results obtained by CNR-IRET with microsatellite analysis indicated the first four genotypes as three-way hybrids $($ J regia $\times J$. nigra $\times$ $J$. major) (Gaudet et al., 2018), whereas 
Table 2. Necrosis length and Tukey-Kramer Grouping $(\alpha=0.01)$ of 38 walnut genotypes subjected to selection for Phytophthora cinnamomi resistance by mycelial plug artificial inoculation on 1 -year-old excised shoots.

\begin{tabular}{|c|c|c|}
\hline Walnut genotype & Averaged necrosis length (mm) & Tukey-Kramer grouping \\
\hline$\overline{\mathrm{Jr}^{\mathrm{z}} 74}$ & 104.6 & $\mathrm{a}$ \\
\hline $\mathrm{Jr} 75$ & 101.5 & $a b$ \\
\hline $\mathrm{H}^{\mathrm{y}} 9 / 36$ & 95.2 & $a b c$ \\
\hline H $9 / 40$ & 88.1 & abcd \\
\hline Jr 76 & 81.9 & abcde \\
\hline H $16 / 68$ & 79.9 & abcdef \\
\hline H 8/32 & 75.8 & abcdefg \\
\hline H 9/34 & 73.2 & bcdefgh \\
\hline H $12 / 52$ & 73.1 & bcdefgh \\
\hline H 1/04 & 70.7 & cdefghi \\
\hline H $15 / 63$ & 64.4 & defghij \\
\hline H $14 / 60$ & 63.4 & defghij \\
\hline $\mathrm{Jmi}^{\mathrm{x}} 10$ & 62.8 & defghij \\
\hline H $10 / 44$ & 62.7 & defghij \\
\hline Jmi 9 & 62.5 & defghij \\
\hline H 2/05 & 62.2 & defghij \\
\hline H 9/38 & 61.6 & defghij \\
\hline H 5/19 & 61.4 & defghij \\
\hline H 4/15 & 57.2 & efghijk \\
\hline H 1/01 & 56.7 & efghijk \\
\hline H 2/07 & 51.6 & efghijk \\
\hline Jmi 5 & 51.5 & efghijk \\
\hline Jmi 1 & 51.4 & fghijk \\
\hline Jmi 4 & 49.9 & fghijk \\
\hline Jmi 6 & 49.8 & fghijk \\
\hline H 7/28 & 49.7 & fghijk \\
\hline Jmi 3 & 47.9 & ghijk \\
\hline H 5/17 & 47.7 & ghijk \\
\hline H 5/20 & 46.2 & ghijk \\
\hline Jmi 2 & 46.1 & ghijk \\
\hline H 8/29 & 43.6 & hijk \\
\hline H 5/18 & 41.5 & ijk \\
\hline H 6/22 & 41.1 & ijk \\
\hline Jmi 11 & 39.4 & $\mathrm{jk}$ \\
\hline Jmi 7 & 39.3 & $\mathrm{jk}$ \\
\hline Jmi 8 & 38.7 & $\mathrm{jk}$ \\
\hline Jmi 12 & 34.5 & $\mathrm{jk}$ \\
\hline H $10 / 43$ & 29.1 & $\mathrm{k}$ \\
\hline
\end{tabular}

${ }_{\mathrm{z}}^{\mathrm{Jr}}=$ Juglans regia.

${ }^{\mathrm{y}} \mathrm{H}=$ hybrid genotypes $($. regia $\times$ Juglans nigra and/or $\times$ Juglans major $)$.

${ }^{\mathrm{x}} \mathrm{Jmi}=$ Juglans microcarpa var. microcarpa .
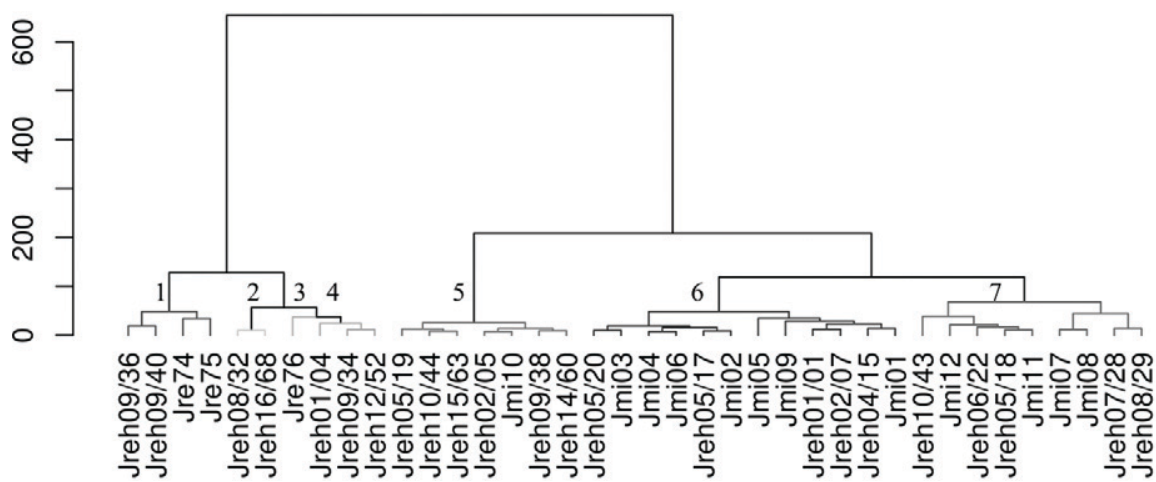

Fig. 2. Dendrogram with Euclidean distance by CLUSTSIG on 38 Juglans spp. genotypes subjected to mycelial plug inoculation. Variables used to cluster genotypes were the four necrosis lengths calculated as means for each season and for each of the two Phytophthora cinnamomi isolates. Seven significantly different clusters were identified at $P \leq 0.05$. Group 7 includes Juglans genotypes most resistant to $P$. cinnamomi colonization. Jreh $=\mathrm{H}=$ hybrid genotypes (Juglans regia $\times$ Juglans nigra and/or $\times$ Juglans major $) ;$ Jre $=J$. regia; Jmi = Juglans microcarpa var. microcarpa.

H6/22 resulted most closely to J. regia, making this genotype particularly promising for a lower risk of blackline when grafted with $J$. regia commercial cultivars. This work pointed out a seasonal influence on some Juglans genotype response to $P$. cinnamomi, condition that must be considered when selecting Juglans for resistance to this pathogen. Experimental observations, conducted on progenies of group 7 parental genotypes, as per experience acquired by the staff assigned to grafts, indicated a high compatibility with scions of Chandler and Lara (S. Vitale, personal communication). In addition, $\mathrm{H} 5 / 17 \mathrm{did}$ not develop any blackline reaction when grafted with Cherry leaf roll virus (CLRV)infected Chandler scions, after 4 years of observations. Blackline disease, caused by CLRV, is considered a serious threat limiting English walnut ( $J$. regia L.) production in Italy and the European Union if walnut species other than J. regia are used as rootstock (Ferretti et al., 2017). Furthermore, transmissibility of CLRV by pollen as well as the possibility of latent infections can easily result in the spread of CLRV contaminated propagative material, a major factor in virus dispersal by human activities. In addition, virus-infected pollen provides a mechanism for the spread from infected to adjacent healthy orchard trees (Srecko et al., 1980). Progenies of resistant mother plants $\mathrm{H} 5 / 18,7 / 28,8 / 29$, $10 / 43$, and $6 / 22$ are currently tested for resistance to $P$. cinnamomi in naturally infested fields. Progenies derived from mother plants of group 7 were used as rootstocks, grafted with Chandler and/or Lara scions, then planted in a commercial walnut orchard area decimated by the pathogen (S. Vitale, personal communication). The combination of CLRV tolerance and resistance to $P$. cinnamomi would be very valuable in orchards affected by both pathogens, also in other regions where walnuts are grown, such as California and Chile.

Two orchards with seedlings from the resistant mother tree clones have been planted in different sites to obtain open-pollinated progenies from each of these promising mother plants to screen for resistance and other horticultural qualities. In this work, a resistance test based on excised shoot inoculations have been used and give excellent results, for its repeatability and robustness. Even though this test could be less realistic, it is less space- and time-consuming than the test in pots used by Browne et al. (2015) and Alvarado et al. (2020) and allows testing resistance of mature plants. Selected progenies will be further evaluated not only for $P$. cinnamomi resistance, but also against other common Phytophthora species (e.g., Phytophthora pini, Phytophthora megasperma, Phytophthora gonapodyides), which are reported as destructive in walnut nurseries and commercial plantations (Belisario et al., 2006, 2012, 2016; Vettraino et al., 2003). In vitro-propagated clonal selections of $\mathrm{J}$. $\mathrm{mi}$ crocarpa genotypes will be tested as soon as they are available.

\section{Literature Cited}

Alvarado, L., S. Saa, I.F. Cuneo, R. Morales, A. Larach, W. Barros, J. Guajardo, and X. Besoain. 2020. A comparison of immediate and short-term defensive responses to Phytophthora species infection in both susceptible and resistant walnut rootstocks. Plant Dis. 104(3): 921-929, doi: 10.1094/PDIS-03-19-0455-RE.

Belisario, A., L. Luongo, S. Vitale, M. Galli, and A. Haegi. 2016. Phytophthora gonapodyides causes 
decline and death of English (Persian) walnut (Juglans regia L.) in Italy. Plant Dis. 100(12): 2537, doi: 10.1094/PDIS-03-16-0394-PDN.

Belisario, A., L. Luongo, M. Galli, and S. Vitale. 2012. First report of Phytophthora megasperma associated with decline and death of common walnut trees in Italy. Plant Dis. 96:1695, doi: 10.1094/PDIS-05-12-0470-PDN.

Belisario, A., M. Galli, and E. Wajnberg. 2009. Evaluation of Juglans species for resistance to Phytophthora cinnamomi: Differences in isolate virulence and response to fosetyl-Al. For. Pathol. 39:168-176, doi: 10.1111/j.1439-0329. 2008.00573.x.

Belisario, A., M. Maccaroni, A.M. Vettraino, A. Valier, and A. Vannini. 2006. Phytophthora species associated with decline and death of English walnut in Italy and France. Acta Hort. 705:401407, doi: 10.17660/ActaHortic.2005.705.57.

Browne, G.T., C.A. Leslie, J.A. Grant, R.G. Bhat, L.S. Schmidt, W.P. Hackett, and G.H. McGranahan. 2015. Resistance to species of Phytophthora identified among clones of Juglans microcarpa $\times$ J. regia. HortScience 50:11361142, doi: 10.21273/HORTSCI.50.8.1136.

Browne, G.T., J.A. Grant, L.S. Schmidt, C.A. Leslie, and G.H. McGranahan. 2011. Resistance to Phytophthora; and graft compatibility with Persian walnut among selections of Chinese wingnut. HortScience 46:371-376, doi: 10.21273/ HORTSCI.46.3.371.

Burgess, T.I., J.K. Scott, K.L. McDougall, M.J. Stukely, C. Crane, W.A. Dunstan, and G.E. Hardy. 2017. Current and future projected global distribution of Phytophthora cinnamomi, one of the world's worst plant pathogens. Glob. Change Biol. 23:1661-1674, doi: 10.1111/ gcb.13492.

Clarke, K.R., P.J. Somerfield, and R.N. Gorley. 2008. Testing of null hypothesis in exploratory 562 community analyses: Similarity profiles and biota-environment linkage. J. Exp. Mar. Biol. Ecol. 366:56-69, doi: 10.1016/j.jembe.2008.07.009.

Core Team R. 2013. R: A language and environment for statistical computing. R Foundation for 1301 Statistical Computing, Vienna, Austria. <http://www.R-project.org/>.

Ebrahimi, A., S. Mathur, S.S. Lawson, N.R. LaBonte, A. Lorch, M.V. Coggeshall, and K.E. Woeste. 2019. Microsatellite borders and micro-sequence conservation in Juglans. Sci. Rep. 9(1):3748, doi: 10.1038/s41598-01939793-z.

Ferretti, L., B. Corsi, L. Luongo, C. Dal Cortivo, and A. Belisario. 2017. A survey of Cherry Leaf Roll virus in intensively managed grafted English (Persian) walnut trees in Italy. J. Plant Pathol. 99:423-427.

Gaudet, M., M.E. Malvolti, M. Gras, E. Carboni, and A. Belisario. 2018. Caratterizzazione molecolare di Juglans spp., conservate in Italia, per lo sviluppo di nuovi portainnesti ibridi resistenti a malattie, adatti alla nocicoltura italiana. XII Convegno Nazionale Biodiversità, Ambiente, Salute, Teramo, 13-15 Giugno.

Gentile, A., A. Frattarelli, G. Urbinati, and E. Caboni. 2020. Effect of $\mathrm{CaCl}_{2}$, paclobutrazol and salicylic acid on in vitro rooting of walnut (Juglans regia L.). Acta Hort. 1285:1-8, doi: 10.17660/ActaHortic.2020.1285.1.

Guajardo, J., S. Saa, R. Camps, and X. Besoain. 2017. Outbreak of 363 crown and root rot of walnut caused by Phytophthora cinnamomi in Chile. Plant Dis. 101:636, doi: 10.1094/PDIS09-16-1242-PDN.

Hardham, A.R. and L.M. Blackman. 2018. Pathogen profile update Phytophthora cinnamomi. Mol. Plant Pathol. 19:260-285, doi: 10.1111/ mpp.12568Jung

Jung, T., I.J. Coloquhoun, and G.E. St. J. Hardy. 2013. New insights into the survival strategy of the invasive soilborne pathogen Phytophthora cinnamomi in different natural ecosystems in Western Australia. For. Pathol. 43:266-288, doi: 10.1111/efp.12025.

Jung, T., L. Orlikowski, B. Henricot, and A. Peréz-Sierra. 2016. Widespread Phytophthora infestations in European nurseries put forest, semi-natural and horticultural ecosystems at high risk of Phytophthora diseases. For. Pathol. 46:134-163.

Kamoun, S., O. Furzer, J.D.G. Jones, H.S. Judelson, G.S. Ali, R.J.D. Dalio, and F. Govers. 2015. The Top 10 oomycete pathogens in molecular plant pathology. Mol. Plant Pathol. 16:413-434, doi: 10.1111/mpp. 12190 .

Legendre, P. and L. Legendre. 1998. Numerical Ecology, Volume 24. 2nd ed. Elsevier Science, Amsterdam, Netherlands.
Matheron, M.E. and S.M. Mircetich. 1985a. Pathogenicity and relative virulence of Phytophthora spp. from walnut and other plants to rootstocks of English walnut trees. Phytopathology 75: 977-981.

Matheron, M.E. and S.M. Mircetich. 1985b. Seasonal variation in susceptibility of Juglans hindsii and Paradox rootstocks to English walnut trees to $P$. citricola. Phytopathology 75 : 970-972.

Mircetich, S.M., G.T. Browne, M.E. Matheron, and B.L. Teviotdale. 1998. Armillaria and Phytophthora root and crown rot diseases, p. 221232. In: D.E. Ramos (ed.). Walnut production manual. University of California, Oakland, CA.

Mircetich, S.M. and M.E. Matheron. 1983. Phytophthora root and crown rot of walnut trees. Phytopathology 73:1481-1488.

SAS Institute Inc. 2002-2012. SAS/STAT® 9.4 SAS Institute Inc, Cary, NC.

Scanu, B., B.T. Linaldeddu, A. Franceschini, N. Anselmi, A. Vannini, and A.M. Vettraino. 2013. Occurrence of Phytophthora cinnamomi in cork oak forests in Italy. For. Pathol. 43: 340-343, doi: 10.1111/efp.12039.

Schena, L., J.M. Duncan, and D.E.L. Cooke. 2008. Development and application of a PCR-based 'molecular tool box' for the identification of Phytophthora species damaging forests and natural ecosystems. Plant Pathol. 57:64-75, doi: 10.1111/j.1365-3059.2007.01689.x.

Srecko, M., S.M. Mircetich, R.R. Sanborn, and D.E. Ramos. 1980. Natural spread, graft transmission, a possible etiology of walnut blackline disease. Phytopathology 70:962-968.

Vettraino, A.M., A. Belisario, M. Maccaroni, and A. Vannini. 2003. Evaluation of root damage to English walnut caused by five Phytophthora species. Plant Pathol. 52:491-495.

Vettraino, A.M., G. Natili, N. Anselmi, and A. Vannini. 2001. Recovery and pathogenicity of Phytophthora species associated with a resurgence of ink disease on Castanea sativa in Italy. Plant Pathol. 50:90-96.

Vitale, S., M. Scotton, A.M. Vettraino, A. Vannini, A. Haegi, L. Luongo, M. Scarpari, and A. Belisario. 2018. Characterization of Phytophthora cinnamomi from common walnut in Southern Europe environment. For. Pathol. 49(1): e12477, doi: 10.1111/efp.12477. 